University of Nebraska - Lincoln

DigitalCommons@University of Nebraska - Lincoln

2006

Selective Attention, Priming, and Foraging Behavior

Alan Kamil

University of Nebraska - Lincoln, akamil1@unl.edu

Alan B. Bond

University of Nebraska - Lincoln, abond1@unl.edu

Follow this and additional works at: https://digitalcommons.unl.edu/bioscibehavior

Part of the Behavior and Ethology Commons

Kamil, Alan and Bond, Alan B., "Selective Attention, Priming, and Foraging Behavior" (2006). Papers in Behavior and Biological Sciences. 40.

https://digitalcommons.unl.edu/bioscibehavior/40

This Article is brought to you for free and open access by the Papers in the Biological Sciences at DigitalCommons@University of Nebraska - Lincoln. It has been accepted for inclusion in Papers in Behavior and Biological Sciences by an authorized administrator of DigitalCommons@University of Nebraska - Lincoln. 


\title{
Selective Attention, Priming, and Foraging Behavior
}

\author{
Alan C. Kamil and Alan B. Bond
}

A nimals selectively filter and transform their sensory input, increasing the accuracy with which some stimuli are detected and effectively ignoring others. This filtering process, collectively referred to as "selective attention," takes place at a variety of different levels in the nervous system. It was described in considerable detail by William James over a century ago (James, 1890/1950) and has been a principal focus of research in cognitive psychology for nearly 50 years (Parasuraman \& Davies, 1984; Pashler, 1998; Richards, 1998). Investigations of selective attention have also been central to the study of animal cognition, where the process of attention has been considered to play an important role in a variety of behavioral paradigms (e.g.. Mackintosh, 1975; Riley \& Roitblat, 1978). Most attention research, particularly in the realm of visual search, has been directed to the nature of the filtering processes applied to relatively simple, geometrical stimuli (reviewed in Humphreys \& Bruce, 1989). Such stimuli can easily be varied along independent physical dimensions, allowing the relationship between targets and distracters to be controlled with considerable precision (e.g., Treisman \& Gelade, 1980). However, the role of selective attention in determining responses to more complex visual stimuli, of the sort that organisms regularly deal with in the course of their normal behavioral routines, has been less explored. This neglect is of particular concern because, in the absence of artificial limitations on search time, simple geometrical stimuli do not place a sufficient demand on information processing capacity to demonstrate selective attention effects (Riley \& Leith, 1976).

In addition to their use of simple geometrical stimuli, most attention studies in animals have used tasks with no clear, direct connection to the perceptual world of the species under study. There is, however, substantial literature suggesting that selective attention may play a significant role in nature, particularly in predator-prey interactions. A review of this literature, integrating it with more customary work on attentional psychology, raises questions of considerable interest to both psychologists and biologists. For psychologists, naturalistic experimental methods using more complex, multidimensional stimuli cast light on additional, unanticipated aspects of attentional processes in animals. For biologists, selective attention has long been considered a primary cognitive mechanism underlying the well-known tendency of visually searching predators to concentrate their attacks on relatively common prey types. As a consequence, the circumstances under which selective attention occurs and the magnitude of the enhancement in detection accuracy that results can have significant ecological and evolutionary effects. Our goal in this chapter, therefore, is to integrate data and hypotheses from both the ecological and the cognitive perspectives. When these two groups of literature are considered together, a variety of parallels emerge, parallels that lay the groundwork for a unified account of attentional phenomena in animals. 


\section{Foraging Behavior and Selective Attention}

Studies of foraging behavior have commonly noted that animals tend to take prey in nonrandom sequences, resulting in much longer "runs" of a single prey type than would be expected by chance. Such concentrated foraging on one food type at a time has been demonstrated across a broad range of vertebrate and invertebrate species, including wood pigeons foraging for seeds on the ground (Murton, 1971), bumblebees feeding on different species of flower (Heinrich, Mudge, \& Deringis, 1977), and insectivorous woodland birds searching for moth larvae (Royama, 1970; Tinbergen, 1960). Nonrandom prey sequences can result from passive factors, such as heterogeneity in the spatial distribution of food types or changes in food accessibility with density, but predators also exhibit dynamic, active selection biases, in which they switch from one prey to another in response to changes in relative abundance and availability (Murdoch, 1969; Murdoch \& Oaten, 1974).

One defining feature of an active selection bias is a characteristic form of relationship between the availability of a particular prey type in the environment and the frequency with which it occurs in the predator's diet. Predators that take prey items as they encounter them, without differentiating among types, exhibit a monotonic, uninflected relationship between diet and prey abundance. Holling (1966) termed this a "Type II" functional response and noted that it is broadly characteristic of invertebrate predators. Active selection biases, on the other hand, produce a sigmoid diet function: Rarer prey types are taken less frequently than would be expected by chance, whereas more common types are taken disproportionately often, a pattern that Holling (1965) termed a "Type III" functional response.

Biologists have long been fascinated by sigmoid diet functions, as they exhibit stabilizing dynamics, known as "apostatic selection" (Clarke, 1962), which can directly contribute to the generation and maintenance of diversity in prey populations (Allen \& Clarke, 1968; Clarke, 1962, 1969; Murdoch \& Oaten, 1974; reviewed in Allen, 1988). Sigmoid diet functions can result from a number of different psychological mechanisms (Bond, 1983; Bond \& Riley 1991), but the most interesting possibilities from the perspective of cognitive psychology are two pro- posed mechanisms that have a bearing on the role of attentional processes in foraging behavior. These are hunting by searching image (Tinbergen, 1960) and hunting by expectation (Royama, 1970).

Tinbergen (1960) first suggested the searching image hypothesis to account for the pattern of predation by European tits on insects in pine woodlands. By recording the prey items that foraging birds brought to their nestlings while simultaneously quantifying the actual relative abundance of these insect species in the environment, Tinbergen was able to examine the relationship between the relative density of insects in the woods and the relative frequency of those insects in the diets of the birds on a day-to-day basis. The most common prey species were taken by the tits in a sigmoid pattern that suggested an active selection bias. Tinbergen's collection technique also allowed him to record the sequences in which prey were captured. He found that insectivorous birds tended to bring prey items to the nest in sequential runs of the same type, suggesting that at any given moment the birds were searching for only one kind of prey (Bond, 1983; Dawkins, 1971; Langley, 1996). On the basis of these data, Tinbergen hypothesized that the birds were filtering out alternative stimuli and limiting their search to the visual features characteristic of a single prey type, thereby increasing their ability to detect that prey type and reducing the detectability of alternative prey types. In essence, Tinbergen was proposing that the selection bias was attributable to selective attention (Langley, 1996).

In a subsequent test of this hypothesis. Croze (1970), in a series of ingenious studies with carrion crows, obtained what is still probably the best evidence for searching image in free-ranging animals. The crows were trained to come to a beach and search for painted seashells that covered food rewards. The shells had been made quite cryptic by painting them the same colors as the sand and rocks on the beach. In one of his experiments, Croze used three different colors of shell, which he called morphs. Each day, he laid out 27 of these shells on the beach, scattered among the pebbles and flotsam in a relatively randomized pattern. On some days, the shells comprised a "monomorphic" population in which all of them were the same color (counterbalanced across days). In the other, "trimorphic" condition, all three morphs were equally represented. 
Croze predicted that during trimorphic days, individual crows would take the prey in runs of a single type. He reasoned that when three morphs were present, the first detection of one of the prey by a crow would result in the formation of a searching image for that shell type, and this would precipitate a run of detections of that type. This did not occur; there were no more runs during trimorphic days than would be expected by chance. However, the crows were more successful at finding monomorphic prey than trimorphic prey. Croze speculated (post hoc) that this difference could result from formation of a searching image for the prey present during monomorphic, but not trimorphic conditions, if several consecutive experiences with a prey type are necessary to adopt a searching image. It is possible that if Croze could have controlled the order within which morphs were encountered during trimorphic conditions, he would have obtained more convincing evidence for improvements in detection with successive encounters with the same prey type.

A number of other naturalistic experiments have been conducted to test the searching image hypothesis, generally involving simultaneous presentation of multiple targets of two disparate types. Several studies have obtained results that were clearly consistent with the hypothesis, in that subjects took stimuli in nonrandom sequences, producing runs of a single stimulus type. Dawkins (1971) presented chicks with an array of grains of rice that were dyed either green or orange and were presented on backgrounds of painted stones that either matched or contrasted the grain colors. She observed the chicks ate the grains in significantly longer sequential runs than would have been expected by chance, and subsequent probe experiments suggested that the birds were alternately cuing either to the shape of cryptic grains or to the color contrast of conspicuous ones. In an experiment involving human subjects manually sorting colored wooden beads. Bond (1982) found that subjects spontaneously chose to sort items in non-random sequences, that the speed and accuracy of the sort were increased at longer run lengths, and that the effect of sorting sequence was enhanced when the beads were harder to discriminate.

Most other multiple target studies have not tracked the sequence of items taken but have instead manipulated the relative numbers of targets of the two types. Although much of the early research in this area was flawed by lack of proper controls (Bond, 1983; Krebs, 1973), later, better-designed studies have demonstrated clear active selection biases when animals are allowed to select among a mixture of targets of several different types (reviewed in Allen, 1988). The most striking and consistent finding of these studies has been that active selection biases are most apparent when the targets are cryptic and difficult to detect, implicating a perceptually based process (Bond, 1983; Cooper, 1984; Cooper \& Allen, 1994; Reid \& Shettleworth, 1992). In an extension of Bond's (1983) study of pigeons searching for cryptic, real grains, Langley, Riley, Bond, and Goel (1996) were able to show not just that selection biases were only displayed under cryptic conditions but also that they could be "set" by prior trials on either cryptic or conspicuous targets and that the bias setting was lost if a 3-minute delay was interpolated between setting and testing trials, suggesting that the bias was transitory. Taken as a whole, these naturalistic, multiple target studies supported Tinbergen's searching image hypothesis, although because the sequence of stimuli experienced by the animals could not be fully controlled, the results could not exclude alternative, nonattentional explanations.

The primary alternative to the searching image hypothesis that can also account for nonrandom prey sequences and sigmoid diet functions in freeranging predators is known as "hunting by expectation" (Krebs, 1973; Royama, 1970). In many cases, different types of food or prey tend to be found in different areas or microhabitats. For example, in a field experiment with great tits during the breeding season, Royama (1970) found that the birds appeared to use specific locations where their preferred prey was most often found. He observed that succeeding periods during the breeding season were each characterized by particular prey types being brought to the nest and that most of these prey inhabited distinctively different microhabitats within the environment. Early in the season, the tits focused hunting mainly on oak foliage, then switched to blackthorn, hawthorn, and ash trees during the middle of the season, and finally to ground vegetation at the end of the breeding season.

These data suggested that the great tits tracked prey availability and used environmental cues (presumably some combination of visual and spatial stimuli) to concentrate their search in the most profitable areas at each stage of the breeding sea- 
son. In other words, the birds showed hunting by expectation, appearing to form an association between particular areas and particular reward rates. Other studies have reported similar findings from a variety of settings, including patch selection and responses to leaf damage in insectivorous birds (Heinrich \& Collins, 1983; Kono, Reid, \& Kamil, 1998; Real, Ianazzi, Kamil, \& Heinrich, 1984; Smith \& Dawkins, 1971; Smith \& Sweatmen, 1974). Getty and Pulliam $(1991,1993)$ conducted a detailed aviary study of the foraging behavior of white-throated sparrows on small cryptic or conspicuous seeds and found clear indications that the birds selected habitat patches based on their expected detection rates, with diet composition changing accordingly.

If prey types differ strongly from one another in their relative densities across microhabitats, hunting by expectation will readily produce sigmoid diet functions and nonrandom prey sequences. Suppose that foragers regularly sample their environment to learn which microhabitat is the most profitable and then subsequently concentrate their hunting in that area. If the microhabitat was characterized by a single prey type, that prey type will be taken more often than would be expected from its overall density in the foraging environment. When the given microhabitat becomes less profitable, birds might be expected to switch to another one, characterized by a different suite of prey items. The result would be that prey would tend to be taken in runs of a single type, much as Tinbergen (1960) observed. Thus, hunting by either expectation or searching image could have accounted for Tinbergen's field results, as well as those from other Studies of free-flying birds (e.g., Allen \& Clarke, 1968; Royama, 1970). As was the case with multiple-target studies of searching image, a higher degree of experimental control was required, especially with respect to the sequence of prey types experienced by the predator, to distinguish unequivocally among these possible alternative mechanisms. Progress in the field effectively demanded the use of operant techniques.

\section{Operant Techniques and Foraging Behavior}

One of the earliest areas of animal cognition research in which the interests of psychologists and biologists coalesced was in the study of foraging behavior (see reviews in Kamil, Krebs, \& Pulliam, 1987; Kamil \& Sargent, 1981; Stephens \& Krebs,
1986). For example, diet selection theory (Macarthur \& Pianka, 1966) predicted that choice among different food types should depend on both their caloric reward and their relative availability, a prediction that was confirmed in operant studies by Krebs, Ryan, and Charnov (1974) and by Fantino (1987). The marginal value theorem (Charnov, 1976) predicted that the time a forager should spend investigating a food patch should be a function of the time required to travel between food patches, a prediction confirmed by Krebs, Erichsen, Webber, and Charnov (1977) and Kamil, Lindstrom, and Peters (1985). Risk-sensitive foraging theory (Caraco, 1980) predicted that the responses of foragers to variations in food reward should depend on their energy budget, a prediction confirmed by Caraco, Martindale, and Whitham (1980) and Caraco (1981).

One of the most successful applications of operant procedures to an issue arising from the study of foraging behavior was a test of the searching image hypothesis. The crucial prediction of Tinbergen's (1960) hypothesis was that a series of successive encounters with a single prey type would, of itself, improve the predator's subsequent ability to detect that prey type. Although experimental designs in which multiple stimuli were presented simultaneously could produce results that were consistent with searching image, their inability to control the order in which prey types were encountered prevented a direct test of Tinbergen's primary prediction. Pietrewicz and Kamil $(1977,1979,1981)$ were, therefore, led to develop a technique, loosely based on Herrnstein and Loveland's (1964) procedures for operant learning of concepts, which was designed to simulate the problem of hunting for cryptic prey. The species chosen for this research was the blue jay (Cyanocitta cristata). These birds commonly forage for a broad range of prey items, many of which are quite cryptic, whose presence may be cued by a range of different environmental stimuli (Husband \& Shimizu, 2001; Meyer, 1977; Sargent, 1976; Tarvin \& Woolfenden, 1999). The procedures originally developed were based on the natural predator - prey system of blue jays visually hunting for Catocala moths on tree trunks. Field data (reviewed by Sargent, 1976) show that jays are frequent predators on these moths, which are very cryptic when resting during the daytime on the bark of trees such as oaks, white birches, or maples. 


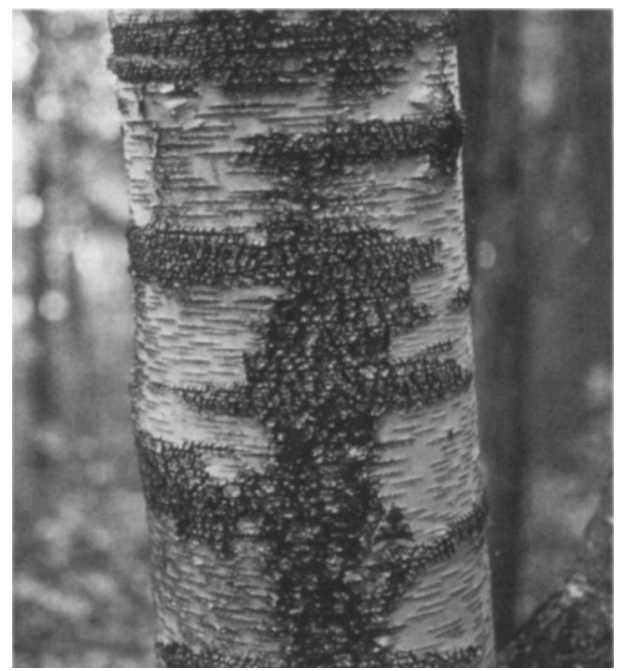

Figure 1. A Catocala relicta moth, resting head-up on a white birch tree. The moth is located on the lower right of the tree trunk.

Pietrewicz and Kamil $(1977,1979)$ trained blue jays to search projected images for Catocala that had been photographed on tree trunks at a range of camera distances (Figure 1). Half of the images included moths; half did not. The jays were rewarded for pecking at images that included moths but not for pecking at images without moths. The birds proved very adept at this task, reliably detecting moths that were highly cryptic to human observers while accurately rejecting images without moths. Pietrewicz and Kamil (1979) used several of the many species of moths in the genus in generating their images, allowing them to conduct a critical test of the searching image hypothesis. Highly experienced blue jays were trained to detect two species of moth that were disparate in appearance: Catocala relicta, a black and white moth that normally rests on birch trees, and C. retecta, a gray, brown, and black moth that normally rests on oak trees. In the middle of sessions during which the two moth types appeared in random order (intermixed with empty slides with no moths), there was a critical sequence of 12 trials - half positive and half negative. In the experimental conditions, the six positive slides each portrayed the same moth type, whereas in the control conditions, the positive slides were half relicta and half retecta, in random order. With this design, the experimental and control conditions were identical except for the ordering of the prey types.
The results clearly supported the searching image hypothesis. When the jays encountered the same type of moth several times in a row during the runs condition, the probability of detecting the moth increased. In addition, the accuracy of the jays in correctly rejecting images without moths also improved in the runs condition. No such changes were observed in the control condition. This provided strong evidence for an improvement in the detectability of a cryptic prey type with successive encounters with that same type. Similar effects have since been obtained in operant studies with pigeons, using cryptic seeds (Bond \& Riley, 1991; Langley, 1996) or alphanumeric characters (P. M. Blough, 1989, 1991) as targets, and the results have been repeatedly confirmed in experiments in blue jays, using more precise control over the relationship between the target stimuli and the background (Bond \& Kamil, 1998, 1999, 2002; Dukas \& Kamil, 2000, 2001).

These findings have firmly established the existence of the searching image effect. It is reasonable to conclude that the increase in detection of a prey type when several exemplars of that type are encountered in succession is at least one of the factors that contributes to the observation that visual predators often take prey, especially cryptic prey, in runs. It is also worth noting that these results are consistent with the results of many studies of natural foraging behavior. In particular, they support Croze's explanation for his failure to obtain clear evidence for searching images in his trimorphic condition. Blue jays generally seem to require several sequential presentations of a particular moth type before their detection significantly improves (although the number of required encounters may depend on the difficulty of the detection task: Bond \& Kamil, 2002). If carrion crows also require multiple successive encounters, then Croze's trimorphic condition would not have provided long enough runs of a single prey type to elicit searching image effects. This example demonstrates how laboratory research can help inform research carried out under natural (but less well-controlled) conditions.

The initial operant studies did not, however, establish the mechanism responsible for the increase in search accuracy. In fact, several alternative explanations for the effect have been put forward. Tinbergen (1960) originally suggested an attentionlike process, a notion strongly supported by P. M. Blough $(1989,1991)$ and Langley (1996). Others have 
suggested that changes in the rate of visual search (Guilford \& Dawkins, 1987) or forgetting during the interval between successive prey stimuli (Plaisted \& Mackintosh, 1995) might produce the apparent increase in detection. We return to this issue later in this chapter.

\section{Attention, Priming, and Searching Image}

The phenomena of hunting by expectation and of searching image each suggest independent contexts in which selective attention may play an important role during visual search for cryptic targets. When the operant literature on selective attention is examined from this perspective, each of these naturalistically based phenomena has an operant analogue, based on the procedure used to prime an attentional state. Priming has usually been defined as the pretrial activation of a representation of the target (Posner \& Snyder, 1975). It was initially identified as an important factor facilitating visual search in experiments with human subjects, where it has been shown that pretrial cues that predict the identity or location of the subsequent target facilitate visual search (Beller, 1971; Eriksen \& Hoffman, 1972). There are two priming procedures that have been used in the animal literature. In the first, an arbitrary cue (or symbol) is associated with one of several potentially available targets, accurately predicting the subsequent occurrence of that target. This has been referred to as "symbolic" or "associative" priming (P. M. Blough, 1989), and it might be expected to occur as a consequence of hunting by expectation. In the second procedure, attention is primed by presenting the same target many times in succession, a process that is often called "sequential” priming (P. M. Blough, 1989; P. M. Blough \& Lacourse, 1994). This appears to correspond to the presumed mechanism of searching image.

\section{Sequential and Associative Priming}

Based on the searching image literature, P. M. Blough (1989) hypothesized that priming might be expected to improve the performance of pigeons that were searching for targets that were difficult to detect. She used a procedure in which the birds searched for two distinctive alphanumeric targets displayed among other similar distracter characters on a computer monitor. Each trial included one target of one of the two types, and trials were terminated by three pecks delivered to one of the on-screen characters. Responses directed at targets were rewarded; if the pigeon mistakenly pecked a distracter, the trial was unrewarded and was subsequently repeated (repeats were omitted from data analyses). Although these procedures differ significantly from natural foraging situations, particularly in the presence of a target in every display, they offer excellent control over many relevant parameters, including the number of possible targets and distracters, the presence of priming stimuli, and the order of target types.

P. M. Blough took full advantage of these possibilities in a series of studies (P. M. Blough, 1989, 1991, 1992, 1996; P. M. Blough \& Lacourse, 1994; Vreven \& Blough, 1998). Here, we emphasize those results that bear most directly on two issues: the differences and/or similarities between different priming procedures and the role of attentional processes in each type of priming. P. M. Blough (1989) tested for effects of sequential and associative priming separately. Her first two experiments established that each type of priming occurred with the procedures she had developed. During these experiments, each trial could contain either of two possible targets: for example, A or L. To test for associative priming, Blough used three cues, one of which preceded each trial. One cue invariably preceded targets that contained A, another invariably preceded trials that contained $\mathrm{L}$, and the third was followed equally often by A and L trials. Targets were detected more rapidly following the predictive cues than following the nonpredictive cue, although the proportion of correct detections was not affected by cue type. To test for sequential priming, targets were presented in sequential runs of a single target type. In this case, significant effects on both search time and accuracy were found, although the effect on accuracy appeared greater and more consistent.

In her third and fourth experiments, P. M. Blough (1989) tested more specifically for whether the effects of associative priming were attentional in nature. She found that following a normally informative prime with the nonprimed target resulted in particularly poor detection of that target and that this effect disappeared if the target was presented alone (with no distracters). These findings supported the hypothesis that the effects of associative priming were due to an attentional process, 
in that a limited capacity attention model (Broadbent, 1958, 1971; Kahneman, 1973) assumes that the detectability of a given target type can only be increased at the cost of a reduction in performance on other targets. P. M. Blough (1991) extended these findings, comparing the effects of several variables on associative and sequential priming. Intertrial interval (ITI) had little effect on sequential priming, but associative priming was more variable and less robust when ITIs were relatively long. Increases in the number of target types improved search during sequential priming but not during associative priming. Blough attributed some of these differences to the different associative demands of the two types of priming and suggested that both types of priming may elicit a similar attentional process.

\section{Priming and Selective Attention}

What is meant by an attentional process in this context? The strongest form of an attentional account of searching image was effectively articulated by Langley (1996). She conceived of visual search as a process of matching sensory input against a cognitive representation of the sought-for target, a representation that through experience has come to incorporate all of the salient features that enable discrimination of the target from the background. In this view, selective attention is a process of "activation" of this representation, bringing it to the cognitive foreground and installing it as the current attentional filter. This view implies that any cue that is predictive of a particular target type-spatial position, recent experience, or even another, arbitrary associated stimulus - will cause activation of the same attentional state. The hypothesis is attractive, but Langley's (1996) results did not compel its adoption, and other studies appear more consistent with an expectancy-based interpretation of sequential priming. P. M. Blough and Lacourse (1994) compared sequential priming with priming based on spatial location and concluded that stimulus-driven factors, such as activation of something like an eidetic image, played little role in sequential priming.

The most conservative, empirically verifiable definition of attention derives from the notion of a limited information processing capacity. According to this definition, selective attention is demonstrated when a condition enhances detection of the primed target and simultaneously interferes with detection of alternative targets. By this definition, there is clear evidence for attention in both sequential and associative priming. In the case of sequential priming, for example, P. M. Blough (1989) demonstrated that "miscuing" after a run of a single target resulted in high search times in pigeons searching for alphanumeric characters among distracters. Reid and Shettleworth (1992) reported similar data for pigeons searching for cryptic seeds, and Bond and Kamil (1999) also found that, after a run of one type of cryptic digital moth, detection of another type was reduced (see also Bond \& Kamil, 2002; Bond \& Riley, 1991; Dukas \& Kamil, 2000, 2001). In the case of associative priming, P. M. Blough (1989) found that response times increased significantly when an associative prime for one target was followed by a different, unexpected target. D. S. Blough (2002) reported similar results when the targets were gratings of different frequency and orientation.

There is strong evidence in favor of interpreting sequential priming or searching image effects as manifestations of an underlying attentional process and the effects of multiple successive encounters with a single prey type are now commonly attributed to selective attention (e.g.. Bond \& Kamil, 2002; Dukas, 2002; Dukas \& Kamil, 2000, 2001; Langley, 1996). Alternative interpretations of the searching image literature have, however, been advanced in the literature. The most broadly cited of these is the argument proposed by Guilford and Dawkins (1987) that changes in search rate could account for many of the findings attributed to searching image.

The effects of variation in the rate of movement of a visual predator through the environment were originally developed in a series of experiments by Gendron and Staddon on the foraging behavior of bobwhite quail (Gendron, 1986; Gendron \&; Staddon, 1983,1984). Gendron and Staddon produced a simple mathematical model, essentially based on a speed/accuracy tradeoff, that demonstrated that for any specific food stimulus, there was an optimal rate of search through the environment that would maximize the rate at which that stimulus was detected. Conspicuous stimuli are detected more readily at greater distances, so they can be searched for more rapidly; difficult, cryptic stimuli, on the other hand, require the bird to slow down and scan its surroundings more thoroughly. This original model was substantially confirmed and greatly ex- 

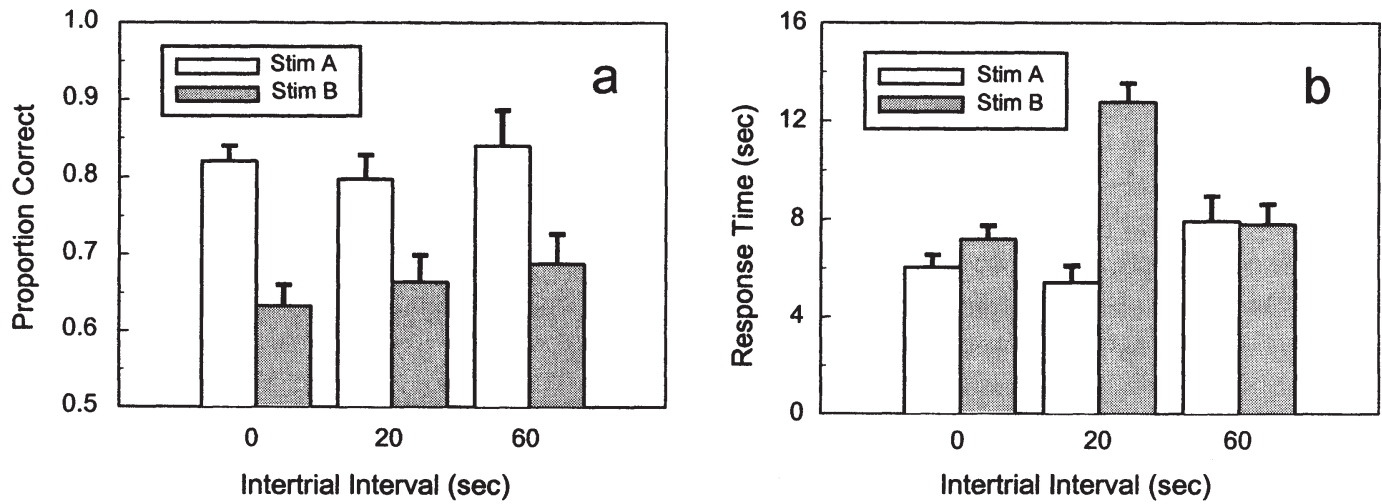

Figure 2. The effects of varying intertrial interval during a run of the same prey type (moth A or B) on probability of detection (a) and the time required to detect the moth (b). Error bars are 1 standard error of the mean. (Redrawn from Cink, 2002.)

panded in subsequent work by Getty and Pulliam (Getty, Kamil, \& Real, 1987; Getty \& Pulliam, 1991, 1993).

Given Gendron's results, Guilford and Dawkins (1987) noted that when two or more prey items that differed in crypticity were present in the environment, repeated encounters with more cryptic items would cause the predator to reduce its search rate to optimize the frequency of detection, while encounters with more conspicuous prey would have the opposite effect. They argued that all of the results (as of 1987, at least) that had been interpreted as evidence of searching image could as readily be seen as consequences of changes in search rate. Subsequent research has demonstrated that their assertions were wholly without merit. In quite different preparations, both Bond and Riley (1991) and Reid and Shettleworth (1992) were able to find indications of independent effects of both search rate and searching image. Improvements in target detection following a run have also been demonstrated in the absence of search rate changes or under conditions in which no change of search rate would be expected (P. M. Blough, 1989, 1992; Bond \& Kamil, 1999; Langley, 1996).

But the most compelling argument against Guilford and Dawkins (1987) is that optimization of search rate does not result in sigmoid diet functions. Gendron and Staddon's $(1983,1984)$ models produce uninflected. Type II functional responses, a result that has since been confirmed by Getty and Pulliam (1993). Fluctuations in the proportion of particular prey types in the diet are passive consequences of changes in search rate, and the Guilford and Dawkins (1987) model cannot, therefore, account for perceptually based, active selection biases (Bond, 1983; Cooper, 1984; Cooper \& Allen, 1994; Reid \& Shettleworth, 1992).

More recently, Plaisted (1997; Plaisted \& Mackintosh, 1995) suggested a forgetting model to account for the results of operant tests of searching image. She pointed out that when targets are presented in runs, the average interval between successive appearances of that target is shorter than when targets of two types are intermixed. In support of her hypothesis, Plaisted cited data showing that pigeons searching for cryptic targets showed clear forgetting effects when the time interval between successive presentations (the ("interstimulus" interval) was directly manipulated. However, the intervals she used were relatively short compared with those used in searching image research in other preparations, and the results of several subsequent experiments indicate that interstimulus intervals may play a relatively minor role in operant studies of searching image.

Two direct tests of the Plaisted hypothesis have been conducted in our laboratory in experiments in which jays hunted for cryptic digital moths. In the first (Bond \& Kamil, 1999), a post hoc analysis of detection data showed that the interstimulus interval had little effect on detection of cryptic digital moths by blue jays. In fact, the effects of interstimulus interval on response time were in the direction opposite from that predicted by Plaisted and Mackintosh (1995). In another study in our laboratory, Cink (2002) directly manipulated the interstimulus interval in detection trials using cryptic digital 
moths and blue jays. The jays were trained to detect two types of moths and were given runs of a single type embedded in long sessions. The moths differed somewhat in their crypticity; one was detected with a probability value of about .65 , and the other with a probability value of .85 . Cink inserted ITIs of 0,20 , or $60 \mathrm{~s}$ between the eighth and ninth moths in a run of the same type. He found that runs led to a significant increase in detection probability but no change in the time required to find a moth. There were no significant effects of the ITI on accuracy on the runs trial following the ITI insertion. In fact, mean probability of detection actually increased with longer ITIs. There were some effects on search time, but their magnitude was small, and, again, the direction of the effect was not as predicted by the Plaisted model. For the prey type that was most difficult to detect, search time was longest after the 20-s ITI (Figure 2). Thus, there is little evidence from operant studies of blue jays to support the interstimulus interval interpretation of searching image effects.

\section{Interactions between Associative and Sequential Priming}

To summarize, two naturally occurring foraging patterns, hunting by expectation and searching image, are related to two phenomena studied under laboratory conditions, associative priming and sequential priming. There is good evidence that each type of priming enlists an attentional process. Because there are many similarities between the results of sequential and of associative priming, the two procedures are often assumed to elicit the same process. For example, D. S. Blough (2002) performed a clever and informative set of experiments designed to separate detection and recognition processes. He obtained generalization gradients on trials during which an associative prime was present, which he compared to gradients when no informative prime was present, as well as to gradients obtained following reinforcement of a single stimulus. Although he never presented runs of a single target, he entitled his paper "Measuring the searching image ...," apparently reflecting this assumption of the equivalence of an underlying process between the different types of priming.

However, there are clear suggestions in the literature of differences between sequential and associa- tive priming (e.g., P. M. Blough, 1991), and this question deserves further study. One approach might be to conduct experiments in which the interactions between associative and sequential priming are studied by making both types of priming available simultaneously. From a naturalistic viewpoint, it seems likely that both types of priming are often available to a foraging animal. If a forager has learned that the most common prey type is available in a specific microhabitat, then the cues associated with that habitat will provide a basis for associative priming. And, once it is hunting in the chosen microhabitat, the forager is likely to encounter the same prey type many times in succession, providing a basis for sequential priming (Kono et al., 1998).

From a mechanistic point of view, the effects of combining both types of priming might be quite informative. If both types elicit the same attentional process, as suggested by P. M. Blough $(1989,1991)$ and Langley (1996), then providing both types of priming simultaneously might be no more effective than providing either one alone. On the other hand, if detection is improved when both types of priming are available, then two possibilities suggest themselves. Either the same attentional process is elicited by either type of priming but is somehow strengthened when both types are presented together, or the two modes of priming elicit separable cognitive processes.

Most research modeled on natural foraging systems has concentrated on sequential priming produced by runs of single target types (e.g.. Bond \& Kamil, 1999; Bond \& Riley, 1991; Kono et al., 1998; Langley, 1996; Pietrewicz \& Kamil, 1979). In contrast, most studies of associative priming have involved a search for simpler stimuli, especially alphanumeric targets. These tasks differ along several dimensions. Tasks based on the detection of cryptic food items require the targets to be differentiated from backgrounds of similar appearance. As D. S. Blough (2002) pointed out, tasks that require the segregation of a coherent target from a random background may have different characteristics from tasks in which a target must be selected from many visible, coherent forms. Until recently, no studies of associative priming had been conducted in which the subjects were required to search for complex naturalistic stimuli on a matching background.

As the first in a series of experiments designed to investigate the interactions between associative 


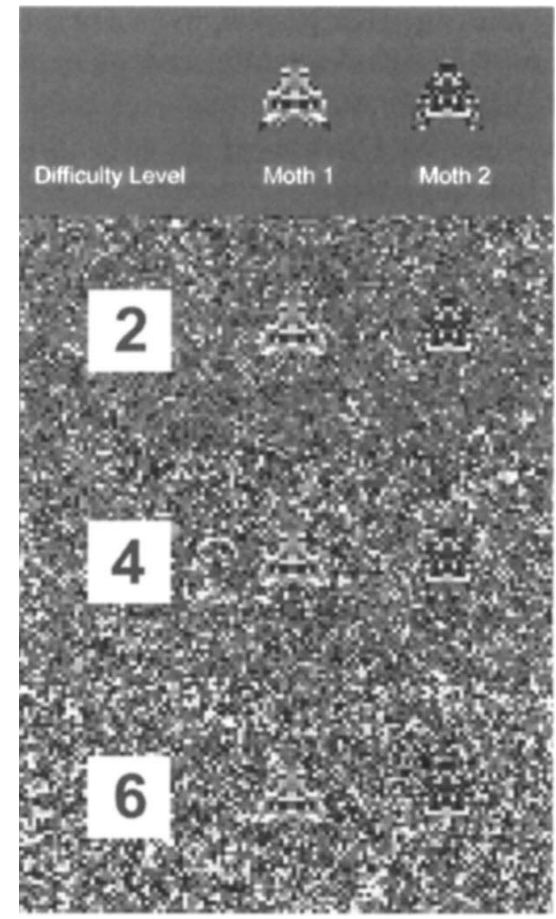

Figure 3. The two digital moths used by Belik (2002), on three different backgrounds of increasing crypticity, top to bottom. (From "Effects of Two Different Types of Priming on Visual Search in the Blue Jay (Cyanocitta cristata)," by M. Belik, 2002, PhD dissertation, University of Nebraska-Lincoln. Reprinted with permission of the author.)

and sequential priming, Belik (2002), working in our laboratory, decided to determine whether associative priming had an effect on blue jays that were searching for cryptic digital moths. In her first set of experiments, she trained jays to find each of two distinctly different moths (Figure 3) displayed on a homogeneous, fractal background on which they were moderately cryptic, using the digital moths developed by Bond and Kamil (1998, 1999). There were two priming stimuli that predicted which moth would be presented in the following trial and two uninformative control stimuli that did not. Each trial began with the presentation of one of these four priming stimuli as a "start" key, and the bird had to peck the stimulus repeatedly to produce the display containing the moths. Each priming stimulus was followed by its designated target on a cryptic background, whereas each uninformative control stimulus was followed equally often by each of the two targets. After training, the birds detected target moths more accurately following primes than following control stimuli, learning to associate the priming stimuli with the appropriate digital moths. This provided the first well-controlled demonstration of associative priming with targets based on background-matching prey.

In a second experiment using the same birds, Belik (2002) then introduced sequential priming in a 2 $\times 2$ factorial design. A series of test trials was embedded within in each daily session. In a control series, neither associative nor sequential priming was provided; the two targets were intermixed in random order and the stimuli on the start key were not informative. In associative-only series, only associative primes were provided; the two targets were sequentially intermixed, but each was reliably signaled by the appropriate associative prime. In sequential-only series, only sequential priming was present. All of the targets in the series were of the same type, but no associative prime was presented. Finally, in associative plus sequential series, both types of priming were present. All of the trials in a series were of a single target type preceded by the appropriate associative prime.

Belik (2002) reasoned that if the two types of priming elicit the same attentional process, then providing both types of priming simultaneously might be no more effective than either one alone. On the other hand, if the multiply primed series produced greater effects than either associative or sequential series alone, then this outcome would suggest that the two modes of priming elicited separable cognitive processes. The results were, however, more complex than she originally envisioned. Introduction of the sequential primes in the factorial design caused the previous associative priming effects to disappear: Neither associative nor sequential primes were superior to control treatments when presented alone, but birds performed more accurately when both types of primes were present than under any other conditions (Figure 4). It appeared that the combination of associative and sequential priming in a single block of trials somehow interfered with the associative priming obtained in the previous stage of the experiment. The failure to find any effect of sequential priming alone suggests that interference also affected performance during runs with no associative cue.

To test this possibility, Belik (2002) returned the jays to a third experiment, consisting again of a series 


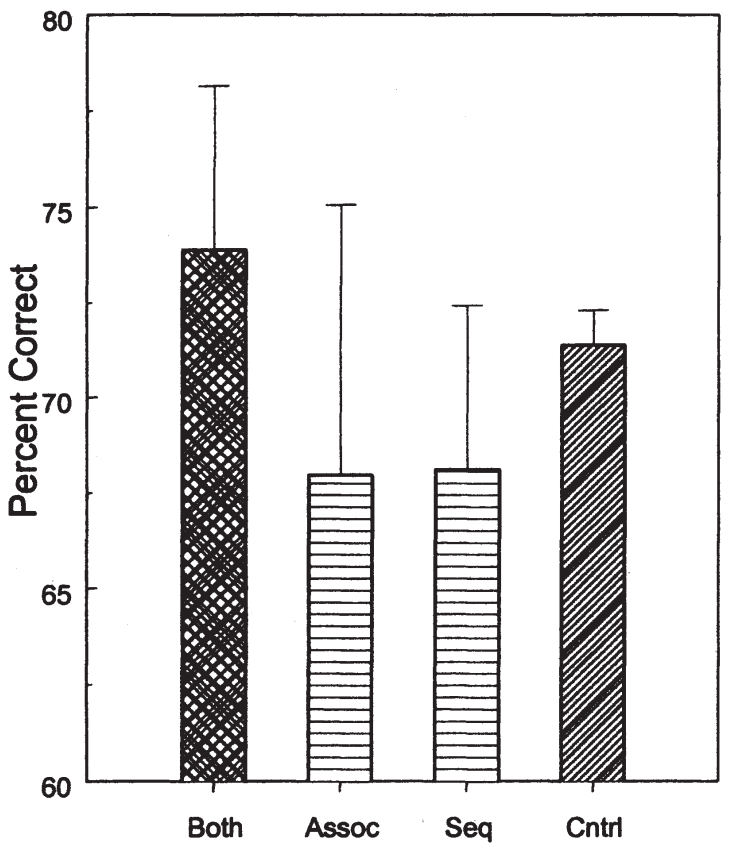

Figure 4. Mean percentage correct as a function of the type of priming present. Jays detected the most moths when both sequential and associative primes were available. However, they performed worse with either sequential or associative priming alone than they did under control conditions, when no priming was available. (Redrawn from Belik, 2002.)

of sessions of associative-only treatments without any sequential patterning. The initial associative priming effect then reappeared, providing support for the notion that the two modes of priming may interfere with one another when they are presented in intermixed sessions to a single subject. This inference is also consistent with the results from Dukas and Kamil (2001), in which there were no costs of switching when cues provided by the background distracters accurately predicted which target type was present.

In another series of experiments, Belik (2002) examined the effects of sequential and associative priming with targets that differed in shape as well as in pattern and with backgrounds that consisted of collections of distracter elements (similar to Dukas \&; Kamil, 2000). In this experiment, both sequential and associative priming produced some improvement in the detection of very cryptic targets (detected on only $40 \%$ to $50 \%$ of trials); the best performance was again evident only when both types of priming were present. One interpretation of these results is that recent prior experience with alternative priming modes interferes to some degree with subsequent elicitation of an attentional state using only a single mode.

\section{Background Matching}

One of the ways in which hunting by expectation might commonly be cued in nature is by the characteristics of the background being searched. For example, many palatable insects prefer to rest on substrates on which they are difficult to detect (e.g., Catocala moths: Sargent, 1976), so that the preferred background would differ for different species. This possibility is supported by the results of a study of background cuing by Dukas and Kamil (2001). Two targets that were disparate in appearance were presented on different backgrounds, so that the appearance of the background predicted which prey type might be present. By alternating trial types in rapid succession over the course of a session, jays were forced to switch between these different targets. There was little cost to this switching, in that the accuracy and speed of visual search were largely unaffected by whether the shifts were frequent or rare. This pattern of results suggests that the associative cues provided by the background may have facilitated a rapid and efficient switching of attention between the prey types.

This hypothesis was supported by the results of another experiment (Dukas \& Kamil, 2001) in which the two targets were presented on the same background, one on which they were equally difficult to detect. Under these conditions, blue jays had to search simultaneously for both cryptic targets, and their overall rate of target detection was reduced by $25 \%$; dividing attentional resources between difficult tasks reduced performance compared with focusing full attention on a single task. The reduction in switching costs when the jays were given an associative cue by the differing backgrounds suggests an attentional priming effect by the different backgrounds.

In contrast, an earlier study on background cuing by Kono et al. (1998) produced paradoxical effects. Jays were trained to search projected photographic images for two moths: C. relicta, a black and white moth normally found on white birch trees, and C. retecta, a brownish gray and black species commonly 
found on oaks. During the experiment, relicta was always displayed on birches, retecta on oaks. Each displayed image included two trees, either both birch, both oak, or one birch and one oak. The birch and oak displays were predictive of which moth might be present; the oak/birch combination was not, as either relicta or retecta (each on its appropriate background) sometimes occurred in this set of images. The results were clear, if puzzling. When runs of a single prey type were presented, the runs had significant effects only when the tree background was predictive of the moth. In addition, there was no evidence that the associative cue provided by the background served as an effective prime; the birds showed no general effect of consistent versus inconsistent background on search accuracy.

At the time, we interpreted these results as demonstrating that the inconsistent background (birch and oak in the same display) somehow interfered with sequential priming. In light of Belik's (2002) results, however, these data could well be another example of an interaction between different types of priming in a within-subjects design. As in Belik's study, only sessions in which both sequential and associative priming cues were present (runs of a single prey type plus a background that predicted prey type) resulted in significant improvement in detection. These results provide further evidence that there may be important interactions of associative and sequential priming.

The results of the studies reviewed in the last two sections of this chapter clearly indicate that further study of the mechanisms leading to sequential and associative priming is needed. We believe that this research also demonstrates the benefits that can accrue to those interested in the cognitive capacities of animals to pursue research that is informed by knowledge of the problems that animals face in nature. Cognition plays an important role in nature, affecting interactions within and between species in many different contexts, ranging from predator-prey interactions and foraging behavior to the acquisition and use of social knowledge (e.g., Balda, Pepperberg \& Kamil, 1998). Conversely, if cognition plays an important role in nature, then students of nature must also become students of cognition. In the concluding section of this chapter, we review some of our research that has taken methods and ideas from the study of animal cognition and applied them to questions of interest to evolutionary biologists.

\section{Biological and Evolutionary Implications}

\section{The Costs of Selective Attention}

One factor that is often ignored in discussions of cognitive evolution is the potential costs of cognitive abilities, a disregard that is probably attributable to lack of knowledge. It is clear that it is expensive to produce and maintain nervous tissue, and to the degree that additional cognitive abilities require additional neural circuitry, the metabolic costs involved could potentially be substantial. Attwell and Laughlin (2001) recently estimated the energetic cost of signaling-related energy use in mammalian brain tissue at approximately $30 \mu \mathrm{mol}$ of ATP/g of tissue/min, which is approximately equal to the energy use by human leg muscles while running a marathon. They also found that a very large percentage of total energy use by the brain is caused by the costs of generating action potentials: To generate an action potential in a single neuron, 1.16 billion $\mathrm{Na}^{+}$ions must be pumped across the cell membrane, requiring 384 million molecules of ATP.

The high cost of neural tissue has important implications for the evolution of cognitive abilities. If a trait is costly to develop and/or maintain, it follows that organisms that exhibit the trait must obtain considerable, compensatory benefits from its possession. Consider, for example, vision in cavedwelling fishes. As a general rule, vision is a highly beneficial trait for fishes, but it is also clearly expensive to develop and maintain both the eye itself and the neural tissue that supports vision, suggesting that vision would be lost quickly in fish that inhabited an environment in which the usual benefits of vision were not available. This loss is exactly what has occurred independently in many different lineages of cave fish. In fact, recent evidence suggests that, even in the case of a single genus, Astyanax, blindness has evolved independently in isolated populations from different caves in Mexico and the southwestern United States (Wilkens \& Strecker, 2003). Analogous considerations of the likely costs of cognitive abilities thus suggest that such abilities must confer consistent, substantial benefits on those individual organisms that possess them if they are to be retained over successive generations of evolution. No cognitive ability would be favored by natural and/or sexual selection, if it did not provide substantial, immediate benefits to the individual. 
In the case of selective attention, there are additional potential costs, in that, for example, foragers searching for difficult, cryptic food items must devote proportionately more of their attention to food finding and thus may be less likely to notice peripheral stimuli. This peripheral disregard might then render them more susceptible to attack from approaching predators. This hypothesis is supported by data from several naturalistic studies during which reactions to model predators were less likely when foragers were engaged in a more challenging foraging task (Krause \& Godin, 1996; Milinski \& Heller, 1978). However, these experiments did not directly control or measure attentional focus, and are therefore subject to alternative interpretations.

Dukas and Kamil (2000) developed a novel approach to directly assessing attentional costs, using an adaptation of our operant prey detection procedures. When blue jays were trained to detect targets that could occur either at the center or in the periphery of a visual display, birds that were searching for central cryptic targets were only one third as likely to detect interpolated trials with peripheral targets as were birds that were searching for central conspicuous targets. The two experimental treatments (easy versus difficult central detection) involved the same background and distracter elements, the same level of conspicuousness of the peripheral targets, and the same frequencies of target appearance within the visual field. The difficult central detection treatment required the bird to dedicate more attention to the center of the visual field, resulting in a reduced frequency of detecting the peripheral targets than during the easy central detection treatment. This experiment thus supports the hypothesis that attending to difficult to find food items carries with it the cost of failing to detect important stimuli, such as those emanating from a predator or social competitor.

\section{The Generation and Maintenance of Phenotypic Diversity}

One of the most fundamental issues in biological evolution is concerned with the mechanisms that contribute to generating biodiversity. Density-dependent processes, which select against more abundant forms and in favor of forms that are rarer, presumably play an important role in encouraging development and maintenance of diversity. Apos- tatic selection, in which a predator concentrates its predation on the most common prey, has long been proposed as a primary example of such densitydependent selection. Many studies have demonstrated such "overselection" by predators, at least to the degree of showing that predators take a larger proportion of the most abundant item in a field of multiple targets (reviewed earlier in this chapter). This does not actually suffice as a demonstration of apostatic selection, however. To maintain diversity, predators would have to cease searching for previously common prey once they became rare, thereby giving the prey a chance to recover. Likewise, they would have to initiate searching for previously rare and ignored prey types when they had increased to some appropriate level of abundance.

A full test of the hypothesis needed to include these features of the dynamic interaction of predators and prey populations, the "switching" process that was actually responsible for producing stable diversity. Dynamic predator-prey interactions were, however, very difficult to emulate in laboratory studies. Based on our earlier operant work, we developed what has proved to be a very successful approach that allows repeatable, laboratory investigations of the selective effects of predation on prey appearance. This "virtual ecology" technique has been used with considerable success to examine the evolutionary origins of cryptic pattern polymorphism (Bond \& Kamil, 1998, 2002; Kamil \& Bond, 2001, 2002).

Digital moths were first used to test the prediction that frequency-dependent predation, in and of itself, can maintain a balanced polymorphism (Bond \& Kamil, 1998). We created a virtual prey population with equal numbers of each of three distinctive morphs and exposed them to daily predation by blue jays. Detected moths were considered "killed" and were subsequently removed from the population. Moths that were overlooked were allowed to breed, bringing the population up to its previous level the following day. Each day thus constituted a generation. Our only experimental intervention was to set the initial numbers of the morphs. In essence, the population of digital moths was a set of asexually reproducing clones of invariant appearance. The number of each morph in each generation was brought up to a constant size based on the relative numbers of surviving individuals in the preceding generation. This design is effectively a "coexistence" experiment (Kassen, 2002), in which the 


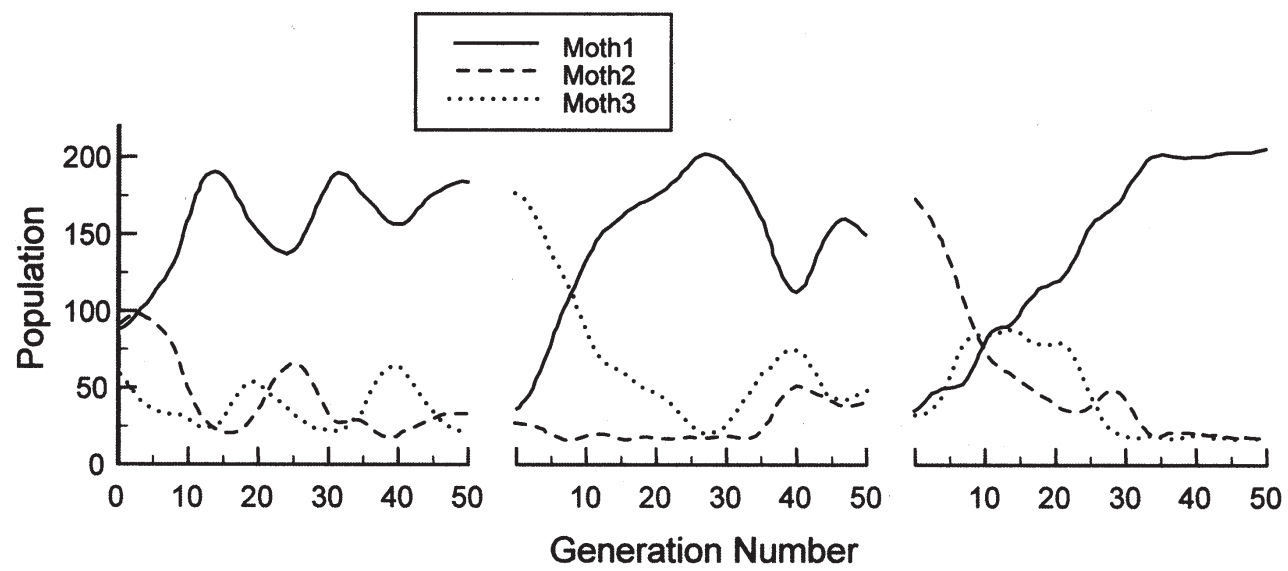

Figure 5. Population numbers of three prey morphs in three successive replications of our virtual prey procedure. Curves were smoothed with weighted least squares, using an eight-generation window. (Redrawn from Bond \& Kamil, 1998).

population dynamics of the different morphs and their asymptotic levels of abundance are the principal dependent variables.

In all three replications, each of which continued for 50 generations, the numbers of the three morphs rapidly achieved a characteristic equilibrium that was independent of initial relative abundances and resistant to perturbation (Figure 5). Additional analyses demonstrated that the equilibrium was a consequence of apostatic selection. One of the morphs happened to be somewhat more difficult to detect than the other two; whatever the starting numbers of the three morphs, this one increased within the population. However, as it increased, the probability of its detection by the blue jays increased, which resulted in the numbers of that morph decreasing, along with the probability of detection. The result was a dynamic, oscillatory equilibrium, maintained entirely by apostatic selection. These experiments constituted the first direct demonstration of the dynamic relationship between searching image, apostatic selection, and prey population stability (Allen, 1988; Cooper and Allen, 1994).

Bond and Kamil (1998) also tested the effects of apostatic selection on novel morphs. We twice introduced small numbers of a new prey type into the population. In each case, they were not initially detected by the jays, and their abundance rapidly increased. In one case, the jays ultimately took notice of the new morph and drove its numbers down, establishing a new equilibrium state. In the second case, the new morph was exceedingly cryptic, most of the jays never learned to detect it, and its numbers increased until it dominated the population (Figure 6). Overall, these results indicated that virtual ecology can be used to study how predator behavior influences prey population dynamics. To extend these procedures to address the evolution of prey appearance, however, we needed to develop a virtual moth genome that would specify digital moth phenotypes.

This genome incorporates many salient features of the developmental genetics of lepidopteran wing patterns (Brakefield et al., 1996; Carroll et al., 1994; Nijhout, 1991; Robinson, 1971), including loci that code for individual patches of pattern elements, loci that produce global changes in wing brightness or contrast without modifying pattern elements, and linkage mechanisms that protect favorable genetic combinations from being lost during recombination. As in real moths, phenotypic characters are polygenic. The genome is divided into nine linkage groups, each of which contains two patch loci and a regulatory locus that include genes for brightness, contrast, and crossing-over probability. Recombination in this system helps to ensure that deleterious patterns are rapidly removed from the population. To preserve integrated pattern features from being broken up by recombination, crossing-over only takes place between linkage groups, and the probability of a cross-over is determined by the combined values of the recombination probability regulators above and below the exchange point. Mutation takes place in bitwise fashion: The algo- 
Figure 6. Population numbers of four morphs when one was a new morph, first introduced during generation 1 . Curves were smoothed with weighted least squares, using an eightgeneration window. Replication 4 (left), included moths 1 to 3 from previous replications and novel moth 4; replication 5 (right) included moths 1 to 3 and novel moth 5. (Redrawn from Bond \& Kamil, 1998.)

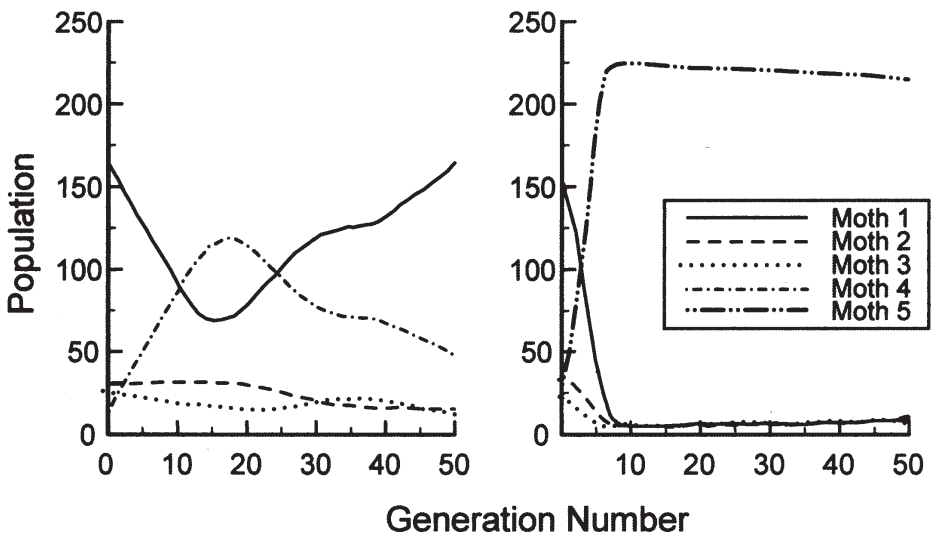

rithm searches down the genome string and, with a fixed, low probability, randomly selects bits to be toggled. We used Gray code for interpreting gene values, which minimizes the coded distance between adjacent integers and reduces the average phenotypic effects of any single mutation (Back, 1996; Mars, Chen, \& Namibar, 1996.

In the first study using this genome (Bond \& Kamil, 2002), we created a parental population of 200 moths with moderate genetic variance and subjected their phenotypes to predation by jays. The speed and accuracy with which each moth was detected determined its fitness - its probability of reproduction. Detected moths had a significantly reduced likelihood of being chosen as parents, and moths that took longer to detect had a higher probability of breeding than those that were detected quickly. Based on these fitness values, pairs of individuals were chosen to breed using a linear ranking algorithm (Back, 1996; Mars et al., 1996). Each pair produced one offspring that was a recombined product of the two parental genotypes. Once the progeny genomes had been obtained, they were passed through a mutation step, with mutation probability of about three events per genome per pairing. Breeding and mutation steps were repeated 200 times, producing the next generation. The previous generation was then discarded, and the new moths were exposed to another round of predation trials. We repeated this experiment three times, each time beginning from the same initial parental population and allowing the jays to determine moth-breeding success for 100 successive progeny generations. This design, in which moth genomes evolve in response to jay predation, is essentially a classic selection experiment (Kassen, 2002). The ef- fects of selection within experimental lines are contrasted to those in control lineages with differing selective regimens.

Our primary interests were whether the moths would show consistent directional selection for increased crypticity and whether the prey population would increase in phenotypic variance, as would be expected from the operation of frequency-dependent, apostatic selection. We developed an empirical measure of crypticity, based on suggestions by Endler (1984, 1990), that compared the distribution of pixel values in the moth with those of the surrounding background. Phenotypic diversity was measured by mean phenotypic distance between each of the individuals in the population and the prototypic "medoid" individual (Kaufman \& Rousseeuw, 1990).

To test whether observed changes in crypticity and phenotypic variance in the experimental lines were meaningful, the results were contrasted to those from two sets of control lineages. In both control treatments, we used the same population size, initial parental population, backgrounds, and mutation rate as in the experimental treatment. The first control was for drift, random changes in the genome due to mutation and recombination. In these nonselected lineages, however, the moths were not presented to the jays; instead, the probability of being chosen to breed was uniform across the moth population, regardless of phenotype. This methodology provided a control for the occurrence of directional selection for crypticity in the experimental treatments. For example, if our parental population happened to be more or less cryptic than the "average random" moth produced by the genotype, then random reproduction would produce some 

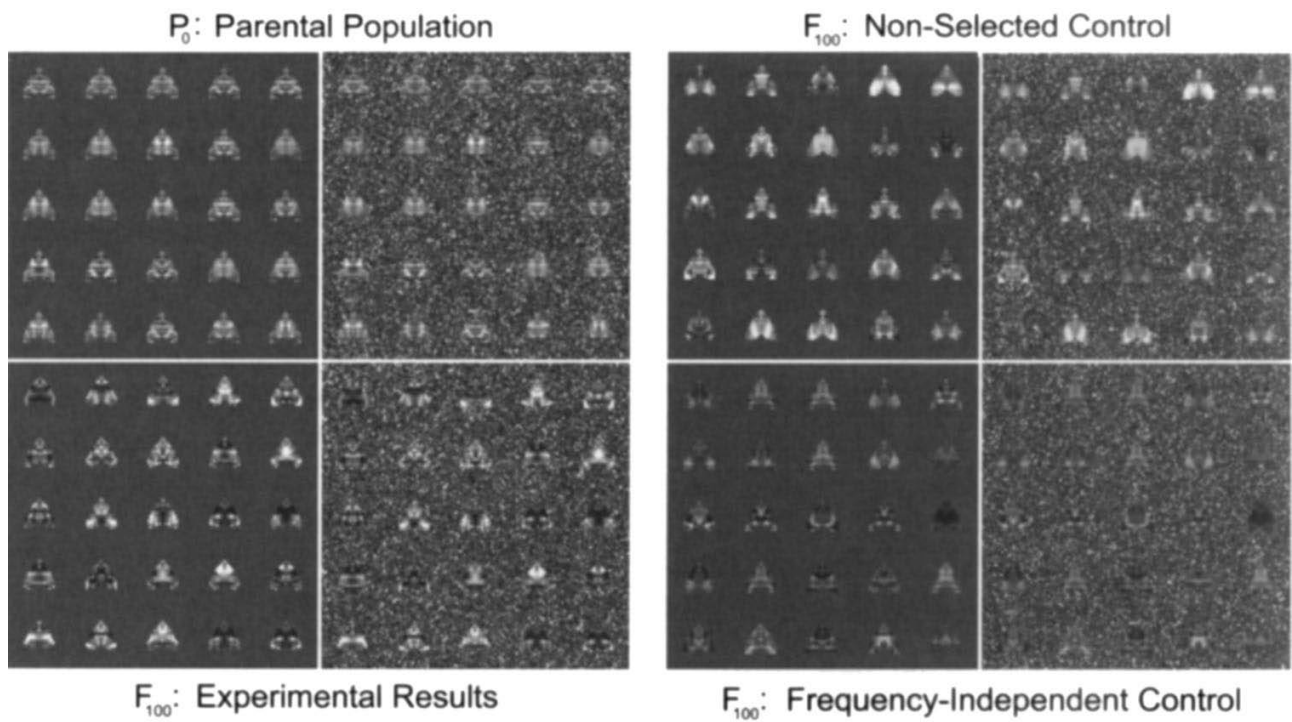

Figure 7. Each of the four panels shows 25 randomly selected moths from a different population. Within each panel, the same moths are shown on a plain gray background (left) and on a cryptic background (right). Top left: Moths from the parental generation, before any selection. Bottom left: Moths from a population that experienced 100 generations of selection by blue jays. Top right: Moths from a population that experienced 100 generations of genetic drift, without selection. Bottom right: Moths from a population that experienced 100 generations of selection by "virtual jays," simulated jays without selective attention. (Redrawn from Bond \& Kamil, 2002.)

changes in crypticity, as a kind of regression toward the mean.

The second control was designed to assess our primary hypothesis - that frequency-dependent selection promotes increased phenotypic diversity. The drift control was not adequate for testing this hypothesis because there are more possible phenotypes than there are phenotypes that are cryptic. Random drift, in and of itself, is expected to result in some increase in variability, so we needed a control that would constrain random drift with the need to appear cryptic. In order to accomplish this aim, our second control involved lineages in which selection was independent of the frequency of particular phenotypes but was otherwise similar in intensity and direction to those produced in the experimental lines. For these control lineages, we determined the functional relationship between detection and crypticity for the jays, averaging over all of the results in the experimental lines. This function was then used to determine the probability of a moth's being chosen to breed. That is, the crypticity of each moth was calculated on the basis of its resemblance to the background, and then a look-up table was used to determine the proba- bility of detection for that moth. That probability of detection was then used to determine the probability of reproduction and the next generation produced by the same algorithm used in the other lineages. In essence, this control was a simulated blue jay that hunted without any density dependence. The detection performance of the simulated jay was determined solely by the degree of resemblance of each moth to the background but was unaffected by any recent experience with moths of differing appearance.

The results were striking and unequivocal for both crypticity and variability (Figures 7 to 9). Over successive generations, the experimental moths evolved to become significantly harder to detect, indicating strong directional selection for increased crypticity. Selection in favor of individuals that resemble the background has been invoked as the probable cause of cryptic coloration in prey species for over a century (Poulton, 1890), and there have been numerous demonstrations that predators preferentially feed on more conspicuous prey items (Cott, 1957; Endler, 1978; Robinson, 1969). Our study is, however, the only work other than Endler's (1980) research on color-pattern selection 

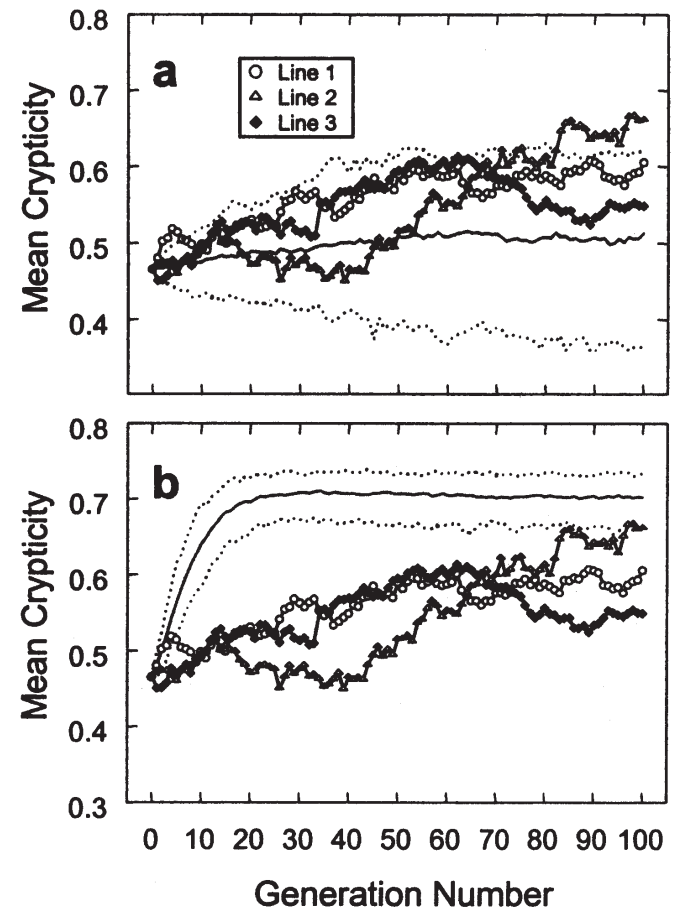

Figure 8. Changes in mean crypticity across successive generations in the three experimental lines (plotted with symbols), contrasted with the distribution of values from the two sets of control lines. Nonselected lines form the control group (a); the control in (b) was produced by frequency-independent selection for crypticity based on parameters derived from global aspects of the jays' behavior. Graphs display medians (solid lines) and 95\% confidence limits (dotted lines) from 200 replicate control lines. Crypticity increased across generations to some degree in all three treatments; the increase was greatest for the frequency-independent controls and least for the nonselected lines. Parameters derived from global aspects of the jays' behavior. (Redrawn from Bond \& Kamil, 2002.)

in guppies that has shown significant directional selection by predators over multiple successive prey generations compared with a nonselected control. But the most important finding was that the experimental lines (Figure 7) showed significantly greater phenotypic variance than either control (Figures 8 and 9), demonstrating that frequency-dependent selection by visual predators can, by itself, promote high phenotypic diversity in prey species. Finally, and most crucially from the perspective of this chapter, additional analyses of the pattern of variation in detection as a function of prey sequences showed that the primary selective effect was due

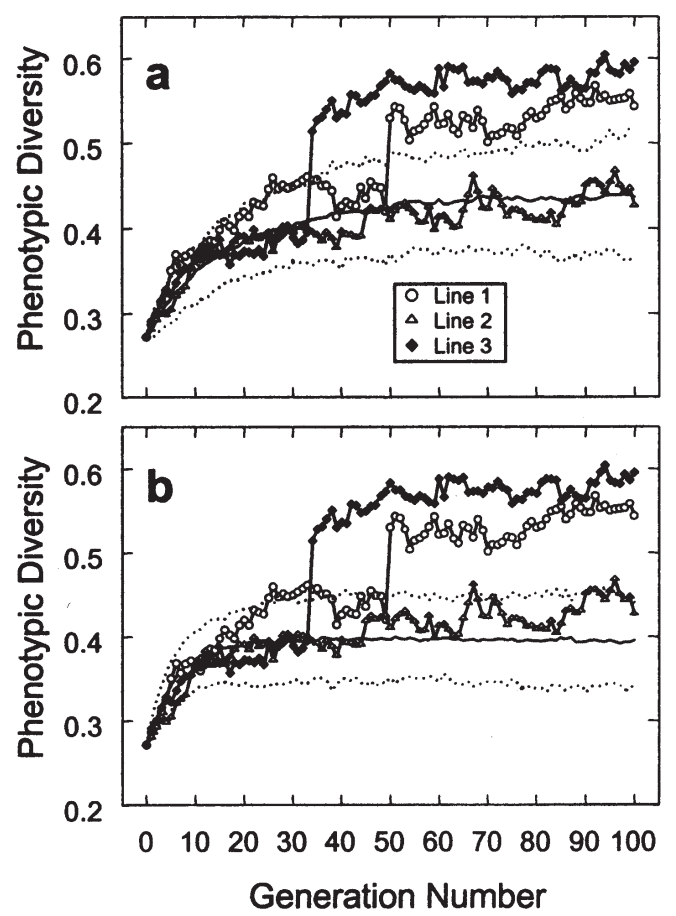

Figure 9. Changes in phenotypic variance across successive generations. Graphs display medians (solid lines) and $95 \%$ confidence limits (dotted lines) from 200 replicate control lines. Phenotypic variance increased to some degree in all three treatments, but the increase was greater in the experimental lines than in the controls. Experimental lines 1 and 3 each exhibited an abrupt shift to a higher level of phenotypic variance at some point in the course of selection trials. (Redrawn from Bond \& Kamil, 2002.)

to jays overlooking atypical cryptic moths. These results thus constitute the most elegant and unequivocal evidence of searching image in the literature and the only demonstration of searching images in which the target stimuli were continuously varying.

\section{Conclusions}

We have chosen to approach the study of animal cognition in an integrative fashion, combining the methodology and insights of experimental psychology and evolutionary biology. This combination can be extraordinarily fruitful, yielding novel perspectives that can be applied broadly to the study of learning and memory in animals. In our own work, we have applied it to spatial cognition 
(e.g., Kamil \& Cheng, 2001) and transitive inference (Bond, Kamil, \& Balda, 2003; Paz-y-Miño, Bond, Kamil, \& Balda, 2004), as well as to selective attention. One of our goals in this chapter has been to demonstrate how this integrative approach can lead to innovative and exciting research. Considerations of how foraging animals might use selective attention while searching for cryptic prey have resulted in interesting questions that focus on the mechanisms of selective attention. The field research of Tinbergen (1960) and others, for instance, gave rise to the concept of the searching image and the study of sequential priming. More recently, considerations of how attentional processes might be integrated in nature gave rise to new questions about sequential and associative priming (Belik, 2002).

One special point we would like to emphasize for experimental psychologists is the enormous contribution that the concepts and methods of experimental psychology can bring to important biological questions. Evolutionary biology has sometimes been criticized for generating just-so stories (e.g., Gould \& Lewontin, 1979), post hoc explanations of findings. But the primary difference between a just-so story and a scientific hypothesis is the availability of an empirical test. Untestable hypotheses are just stories. Let someone figure out a way to test an apparently untestable explanation for a phenomenon, however, and a magical transformation occurs: just-so story becomes scientific hypothesis. As our work on the costs of selective attention and on the effects of attentional processes on the evolution of the appearance of prey demonstrates, the ideas and methods of psychology can be used to empirically test many evolutionary ideas, particularly those in which the decisions of one organism have effects on another, through either natural or sexual selection.

\section{Acknowledgments}

The research reported in this chapter has been supported by multiple grants from the National Science Foundation and the National Institute of Mental Health, most recently IBN-0234441 (NSF) and MH68426 (NIMH).

\section{References}

Allen, J. A. (1988). Frequency-dependent selection by predators. Philosophical Transactions of the Royal Society of London B, 319, 485-503.
Allen, J. A., \& Clarke, B. (1968). Evidence for apostatic selection in wild passerines. Nature, 220, 501-502.

Attwell, D., \& Laughlin, S. B. (2001). An energy budget for signaling in the grey matter of the brain. Journal of Cerebral Blood Flow and Metabolism, 21, 1133-1145.

Back, T. (1996). Evolutionary algorithms in theory and practice. New York: Oxford University Press.

Balda, R., Pepperberg, I., \& Kamil, A. C. (1998). Animal cognition in nature. New York: Academic Press.

Belik, M. (2002). Effects of two different types of priming on visual search in the blue jay (Cyanocitta cristata). Unpublished doctoral dissertation. University of Nebraska, Lincoln.

Beller, H. K. (1971). Priming: Effects of advance information on matching. Journal of Experimental Psychology, 57, 976-982.

Blough, D. S. (2002). Measuring the search image: Expectation, detection, and recognition in pigeon visual search. Journal of Experimental Psychology: Animal Behavior Processes, 28, 397-405.

Blough, P. M. (1989). Attentional priming and search images in pigeons. Journal of Experimental Psychology: Animal Behavior Processes, 15, 211-223.

Blough, P. M. (1991). Selective attention and search images in pigeons. Journal of Experimental Psychology: Animal Behavior Processes, 17, 292-298.

Blough, P. M. (1992). Detectability and choice during visual search: Joint effects of sequential priming and discriminability. Animal Learning and Behavior, 20, 293-300.

Blough, P. M. (1996). Priming during multiple-target search: The cumulative effects of relative target frequency. Animal Learning and Behavior, 24, 394-400.

Blough, P. M., \& Lacourse, D. M. (1994). Sequential priming in visual search: Contributions of stimulus-driven facilitation and learned expectancies. Animal Learning and Behavior, 22, 275-281.

Bond, A. B. (1982). The bead game: Response strategies in free assortment. Human Factors, 24, 101-110.

Bond, A. B. (1983). Visual search and selection of natural stimuli in the pigeon: The attention threshold hypothesis. Journal of Experimental Psychology: Animal Behavior Processes, 9, 292-306.

Bond, A. B., \& Kamil, A. C. (1998). Apostatic selection by blue jays produces balanced polymorphism in virtual prey. Nature, 395, 594-596.

Bond, A. B., \& Kamil, A. C. (1999). Searching image in blue jays: Facilitation and interference in sequential priming. Animal Learning and Behavior, 27, 461-471.

Bond, A. B., \& Kamil, A. C. (2002). Visual predators select for crypticity and polymorphism in virtual prey. Nature, 415, 609-614. 
Bond, A. B., Kamil, A. C., \& Balda, R. P. (2003). Social complexity and transitive inference in corvids. Animal Behaviour, 65, 479-487.

Bond, A. B., \& Riley, D. A. (1991). Searching image in the pigeon: A test of three hypothetical mechanisms. Ethology, 87, 203-224.

Brakefield, P. M., Gates, J., Keyes, D., Kesbeke, R, Wijngaarden, P. J., Monteiro, A., et al. (1996). Development, plasticity and evolution of butterfly eyespot patterns. Nature, 384, 236-242.

Broadbent, D. E. (1958). Perception and communication. London: Pergamon.

Broadbent, D. E. (1971). Decision and stress. New York: Academic Press.

Caraco, T. (1980). On foraging time allocation in a stochastic environment. Ecology, 61, 119-128.

Caraco, T. (1981). Energy budgets, risk and foraging preferences in dark-eyed juncos (Junco hyemalis). Behavioral Ecology and Sociobiology, 8, 213-217.

Caraco, T., Martindale, S., \& Whitham, T. S. (1980). An empirical demonstration of risk-sensitive foraging preferences. Animal Behaviour, 28, 820-830.

Carroll, S. B., Gates, J., Paddock, S. W., Panganiban, G. E. E, Selegue, J. E., \& Williams, J. A. (1994). Pattern formation and eyespot determination in butterfly wings. Science, 265, 109-114.

Charnov, E. L. (1976). Optimal foraging: The marginal value theorem. Theoretical Population Biology, 9, 129-136.

Cink, C. (2002). Factors influencing the use of searching images by blue jays hunting for cryptic prey. Unpublished doctoral dissertation, University of Nebraska, Lincoln.

Clarke, B. C. (1962). Balanced polymorphism and the diversity of sympatric species. In D. Nichols (Ed.), Taxonomy and geography (pp. 47-70). Oxford: Systematics Association.

Clarke, B. C. (1969). The evidence for apostatic selection. Heredity, 24, 347-352.

Cooper, J. M. (1984). Apostatic selection on prey that match the background. Biological Journal of the Linnaean Society, 23, 221-228.

Cooper, J. M., \& Allen, J. A. (1994). Selection by wild birds on artificial dimorphic prey on varied backgrounds. Biological Journal of the Linnaean Society, 51, 433-446.

Cott, H. B. (1957). Adaptive coloration in animals. London: Methuen.

Croze, H. J. (1970). Searching image in carrion crows. Zeitschrift für Tierpsychologie Supplement, 5, 1-85.

Dawkins, M. (1971). Shifts in "attention" in chicks during feeding. Animal Behaviour, 19, 575-582.

Dukas, R. (2002). Behavioural and ecological consequences of limited attention. Philosophical Transactions of the Royal Society of London B, 357, 1539-1547.

Dukas, R., \& Kamil, A. C. (2000). The cost of limited attention in blue jays. Behavioral Ecology, 11, 502-506.

Dukas, R., \& Kamil, A. C. (2001). Limited attention: The constraint underlying search image. Behavioral Ecology, 12, 192-199.

Endler, J. A. (1978). A predator's view of animal color patterns. Evolutionary Biology, 11, 319-364.

Endler, J. A. (1980). Natural selection on color patterns in Poecilia reticulata. Evolution, 34, 76-91.

Endler, J. A. (1984). Progressive background matching in moths, and a quantitative measure of crypsis. Biological Journal of the Linnaean Society, 22, 187-231.

Endler, J. A. (1990). On the measurement and classification of colour in studies of animal colour patterns. Biological Journal of the Linnaean Society, 41, 315-352.

Eriksen, C. W., \& Hoffmann, J. E. (1972). Some characteristics of selective attention in visual perception determined by vocal reaction time. Perception and Psychophysics, 11, 169-171.

Fantino, E. (1987). Operant conditioning simulations of foraging and the delay-reduction hypothesis. In A. C. Kamil, J. R. Krebs, \& H. R. Pulliam (Eds.), Foraging behavior (pp. 193-214). New York: Plenum.

Gendron, R. P. (1986). Searching for cryptic prey: Evidence for optimal search rates and the formation of search images in quail. Animal Behaviour, 34, 898-912.

Gendron, R. P., \& Staddon, J. E. R. (1983). Searching for cryptic prey: The effect of search rate. American Naturalist, 121, 172-186.

Gendron, R. P., \& Staddon, J. E. R. (1984). A laboratory simulation of foraging behavior: The effect of search rate on the probability of detecting prey. American Naturalist, 124, 407-415.

Getty, T., Kamil, A. C., \& Real, P. G. (1987). Signal detection theory and foraging for cryptic or mimetic prey. In A. C. Kamil, J. R. Krebs, \& H. R. Pulliam (Eds.), Foraging behavior (pp. 525-548). New York: Plenum.

Getty, T, \& Pulliam, H. R. (1991). Random prey detection with pause-travel search. American Naturalist, 138, 1459-1477.

Getty, T, \& Pulliam, H. R. (1993). Search and prey detection by foraging sparrows. Ecology, 74, 734-742.

Gould, S. J., \& Lewontin, R. C. (1979). The spandrels of San Marco and the Panglossian paradigm: A critique of the adaptionist programme. Proceedings of the Royal Society of London, 205, 581-598. 
Guilford, T., \& Dawkins, M. S. (1987). Search images not proven: A reappraisal of recent evidence. Animal Behaviour, 35, 1838-1845.

Heinrich, B., \& Collins, S. L. (1983). Caterpillar leaf damage and the game of hide-and-seek with birds. Ecology, 64, 592-602.

Heinrich, B., Mudge, P., \& Deringis, P. (1977). A laboratory analysis of flower constancy in foraging bumblebees: Bombus ternarius and B. terricola. Behavioral Ecology, 2, 247-266.

Herrnstein, R. J., \& Loveland, D. H. (1964). Complex visual concepts in the pigeon. Science, 146, 549-551.

Holling, C. S. (1965). The functional response of predators to prey density and its role in mimicry and population regulation. Memoirs of the Entomological Society of Canada, 45, 1-60.

Holling, C. S. (1966). The functional response of invertebrate predators to prey density. Memoirs of the Entomological Society of Canada, 48, 3-86.

Humphreys, G. W., \& Bruce, V. (1989). Visual cognition: Computational, experimental, and neuropsychological perspectives. Hillsdale, NJ: Lawrence Erlbaum.

Husband, S., \& Shimizu, T. (2001). Evolution of the avian visual system. In R. G. Cook (Ed.), Avian visual cognition. Accessed August 30, 2005, at http://www.pigeon.psy.tufts.edu/avc/husband/default.htm

James, W. (1950). Principles of psychology. Vol. I (pp. 402-458). New York: Dover Publications (original work published 1890).

Kahneman, D. (1973). Attention and effort. Englewood Cliffs, NJ: Prentice-Hall.

Kamil, A. C., \& Bond, A. B. (2001). The evolution of virtual ecology. In L. A. Dugatkin (Ed.), Model systems in behavioral ecology (pp. 288-310). Princeton, NJ: Princeton University Press.

Kamil, A. C., \& Bond, A. B. (2002). Cognition as an independent variable: Virtual ecology. In M. Bekoff, C. Allen, \& G. Burghart (Eds.), The cognitive animal: Empirical and theoretical perspectives on animal cognition (pp. 143-149). Cambridge, MA: MIT Press.

Kamil, A. C., \& Cheng, K. 2001. Way-finding and landmarks: The multiple-bearings hypothesis. Journal of Experimental Biology, 204, 103-113.

Kamil, A. C., Krebs, J. R., \& Pulliam, H. R. (1987). Foraging behavior. New York: Plenum.

Kamil, A. C., Lindstrom, E, \& Peters, J. (1985). Foraging for cryptic prey by blue jays. I. The effects of travel time. Animal Behaviour, 33, 1068-1079.

Kamil, A. C., \& Sargent, T. D. (1981). Foraging behavior: Ecological, ethological and psychological approaches. New York: Garland Press.
Kassen, R. (2002). The experimental evolution of specialists, generalists, and the maintenance of diversity. Journal of Evolutionary Biology, 15, 173-190.

Kaufman, L., \& Rousseeuw, P. J. (1990). Finding groups in data: An introduction to cluster analysis. New York: Wiley.

Kono, H., Reid, P. J., \& Kamil, A. C. (1998). The effects of background cuing on prey detection. Animal Behaviour, 56, 963-972.

Krause, J., \& Godin, J. G. J. 1996. Influence of prey foraging posture on flight behavior and predation risk: Predators take advantage of unwary prey. Behavioral Ecology, 7, 264-271.

Krebs, J. R. (1973). Behavioral aspects of predation. In P. P. G. Bateson \& P. H. Klopfer (Eds.), Perspectives in ethology. Vol. 1 (pp. 73-111). New York: Plenum.

Krebs, J. R., Erichsen, J. T, Webber, M. I., \& Charnov, E. L. (1977). Optimal prey selection in the great tit (Parus major). Animal Behaviour, 25, 30-38.

Krebs, J. R., Ryan, J. C., \& Charnov, E. L. (1974). Hunting by expectation or optimal foraging? A study of patch use by chickadees. Animal Behaviour, 22, 953-964.

Langley, C. M. (1996). Search images: Selective attention to specific visual features of prey. Journal of Experimental Psychology-Animal Behavior Processes, 22, 152-163.

Langley, C. M., Riley, D. A., Bond, A. B., \& Goel, N. (1996). Visual search for natural grains in pigeons (Columba livia): Search images and selective attention. Journal of Experimental, Psychology: Animal Behavior Processes, 22, 139-151.

Macarthur, R. H., \& Pianka, E. R. (1966). On optimal use of a patchy environment. American Naturalist, 100, 603-609.

Mackintosh, N. J. (1975). A theory of attention: Variations in the associability of stimuli with reinforcement. Psychological Review, 82, 276-298.

Mars, P., Chen, J. R., \& Namibar, R. (1996). Learning algorithms: Theory and applications in signal processing, control and communications. New York: CRC Press.

Meyer, D. B. C.(1977). The avian eye and its adaptations. In F. Crescitelli (Ed.), The visual system of vertebrates: Handbook of sensory physiology. Vol. VII (pp. 549-611). Berlin: Springer-Verlag.

Milinski, M., \& Heller, R. (1978). Influence of a predator on the optimal foraging behavior of sticklebacks (Gasterosteus aculeatus). Nature, 275, 642-644.

Murdoch, W. W. (1969). Switching in general predators: Experiments on predator specificity and stability of prey populations. Ecological Monographs, 39, 335-354. 
Murdoch, W. W., \& Oaten, A. (1974). Predation and population stability. Advances in Ecological Research, 9, $1-131$.

Murton, R. K. (1971). The significance of a specific search image in the feeding behavior of the wood-pigeon. Behaviour, 40, 10-42.

Nijhout, H. F. (1991). The development and evolution of butterfly wing patterns. Washington, DC: Smithsonian Institution.

Parasuraman, R., \& Davies, D. R. (Eds.) (1984). Varieties of attention. New York: Academic Press.

Pashler, H. E. (1998). The psychology of attention. Cambridge, MA: MIT Press.

Paz-y-Miño, C. G., Bond, A. B., Kamil, A. C., \& Balda, R. P. (2004). Pinyon jays use transitive inference to predict social dominance. Nature, 430, 778-781.

Pietrewicz, A. T, \& Kamil, A. C. (1977). Visual detection of cryptic prey by blue jays (Cyanocitta cristata). Science, 195, 580-582.

Pietrewicz, A. T, \& Kamil, A. C. (1979). Search image formation in the blue jay (Cyanocitta cristata). Science, 204, 1332-1333.

Pietrewicz, A. T, \& Kamil, A. C. (1981). Search images and the detection of cryptic prey: An operant approach. In A. C. Kamil \& T. D. Sargent (Eds.), Foraging behavior: Ecological, ethological and psychological approaches (pp. 311-332;. New York: Garland.

Plaisted, K. (1997). The effect of interstimulus interval on the discrimination of cryptic targets. Journal of Experimental Psychology: Animal Behavior Processes, $23,248-259$.

Plaisted, K. C., \& Mackintosh, N. J. (1995). Visual search for cryptic stimuli in pigeons: Implications for the search image and search rate hypotheses. Animal Behaviour, 50, 1219-1232.

Posner, M. I., \& Snyder, C. R. R. (1975). Facilitation and inhibition in the processing of signals. In P. M. R. S. Domic (Ed.), Attention and performance, V (pp. 669682). San Diego, CA: Academic Press.

Poulton, E. B. (1890). The colours of animals: Their meaning and use, especially considered in the case of insects. New York: Appleton.

Real, P. G., Ianazzi, R., Kamil, A. C., \& Heinrich, B. (1984). Discrimination and generalization of leaf damage by blue jays. Animal Learning and Behavior, 12, 202-208.

Reid, P. J., \& Shettleworth, S. J. (1992). Detection of cryptic prey: Search image or search rate? Journal of Experimental Psychology; Animal Behavior Processes, $18,273-286$.
Richards, J. E. (Ed.). (1998). Cognitive neuroscience of attention. Mahwah, NJ: Lawrence Erlbaum.

Riley, D. A., \& Leith, C. R. (1976). Multidimensional psychophysics and selective attention in animals. Psychological Bulletin, 83, 138-160.

Riley, D. A., \& Roitblat, H. L. (1978). Selective attention and related cognitive processes in pigeons. In S. H. Hulse, H. Fowler, \& W. K. Honig (Eds.), Cognitive processes in animal behavior (pp. 249-276). Hillsdale, NJ: Lawrence Erlbaum.

Robinson, M. H. (1969). Defenses against visually hunting predators. Evolutionary Biology, 3, 225-259.

Robinson, R. (1971). Lepidopteran genetics. Oxford: Pergamon Press.

Royama, T. (1970). Factors governing the hunting behavior and selection of food by the great tit (Parus major L.). Journal of Animal Ecology, 39, 619-668.

Sargent, T. D. (1976). Legion of night. Amherst, MA: University of Massachusetts Press.

Smith, J. N. M., \& Dawkins, R. (1971). The hunting behavior of individual great tits in relation to spatial variations in their food density. Animal Behaviour, 19, 695-706.

Smith, J. N. M., \& Sweatman, H. P. A. (1974). Food searching behavior of titmice in patchy environments. Ecology, 55, 1216-1232.

Stephens, D. W., \& Krebs, J. R. (1986). Foraging theory. Princeton, NJ: Princeton University Press.

Tarvin, K. A., \& Woolfenden, G. E. (1999). Blue jay (Cyanocitta cristata). In A. Poole \& F. Gill (Eds.), The birds of North America, No. 469. Philadelphia, PA: The Birds of North America, Inc.

Tinbergen, L. (1960). The natural control of insects in pinewoods. 1. Factors influencing the intensity of predation by songbirds. Archives Néerlandaises de Zoologie, 13, 265-343.

Treisman, A., \& Gelade, G. (1980). A feature-integration theory of attention. Cognitive Psychology, 12, 97-136.

Vreven, D., \& Blough, P. M. (1998). Searching for one or many targets: Effects of extended experience on the runs advantage. Journal of Experimental Psychology: Animal Behavior Processes, 24, 98-105.

Wilkens, H., \& Strecker, U. (2003). Convergent evolution of the cavefish Astyanax (Charicidae, Teleostei): Genetic evidence from reduced eye-size and pigmentation. Biological Journal of the Linnean Society, 80, 545-554. 